\title{
Eindrücke der Venetien-Reise 2009 der Freunde des Palmengartens
}

LOLITA SEBASTIAN

\section{Auf nach Italien}

Die wie in den Vorjahren für die Freunde des Palmengartens organisierte Reise führte diesmal vom 30. August bis 5. September 2009 mit 34 Teilnehmerinnen und Teilnehmern nach Italien. Erste Station waren in Meran die Gärten von Schloss Trauttmansdorff. Auf dem großen Gelände gab es viel zu erkunden, darunter einen japanischen, italienischen und geheimen Garten. Vertraute Stimmung kommt bei Frankfurter Gartenfreunden auf, wenn man am Teich an einer attraktiven Palmengruppe vorbeikommt, die als Palmengarten bezeichnet wird. Wundervolle Pflanzenarrangements, eine nahezu naturbelassene Vegetation am Felshang, ein Pfad zu urweltlichen Pflanzen wie der Wollemia, grandiose Blicke von einer Aussichtsplattform und bi- zarre Skulpturen verzaubern Besucherinnen und Besucher dieses Gartens. Die Zeit war leider zu kurz, um alles aufzunehmen, denn unser Ziel war schließlich Venetien und wir mussten weiter. Die Fahrt dorthin führte durch das abwechslungsreiche Alto Adige. Es gab einen Zwischenstop in Valpolicella, wo eine Weinprobe sowie eine von der Contessa geführte Gartenbesichtigung der Villa Rizzardi auf dem Programm standen. In Verona erfolgte noch ein Abstecher zu den Giardini dei Giusti. Unser Hotel in Abano Terme ließ dann die lange Anfahrt vergessen.

\section{Venedig und Umgebung}

Während eines Rundganges erlebten wir Padua, die stolze Stadt. Unter alten Bäumen im Botanischen Garten - GoETHEs Palme steht noch

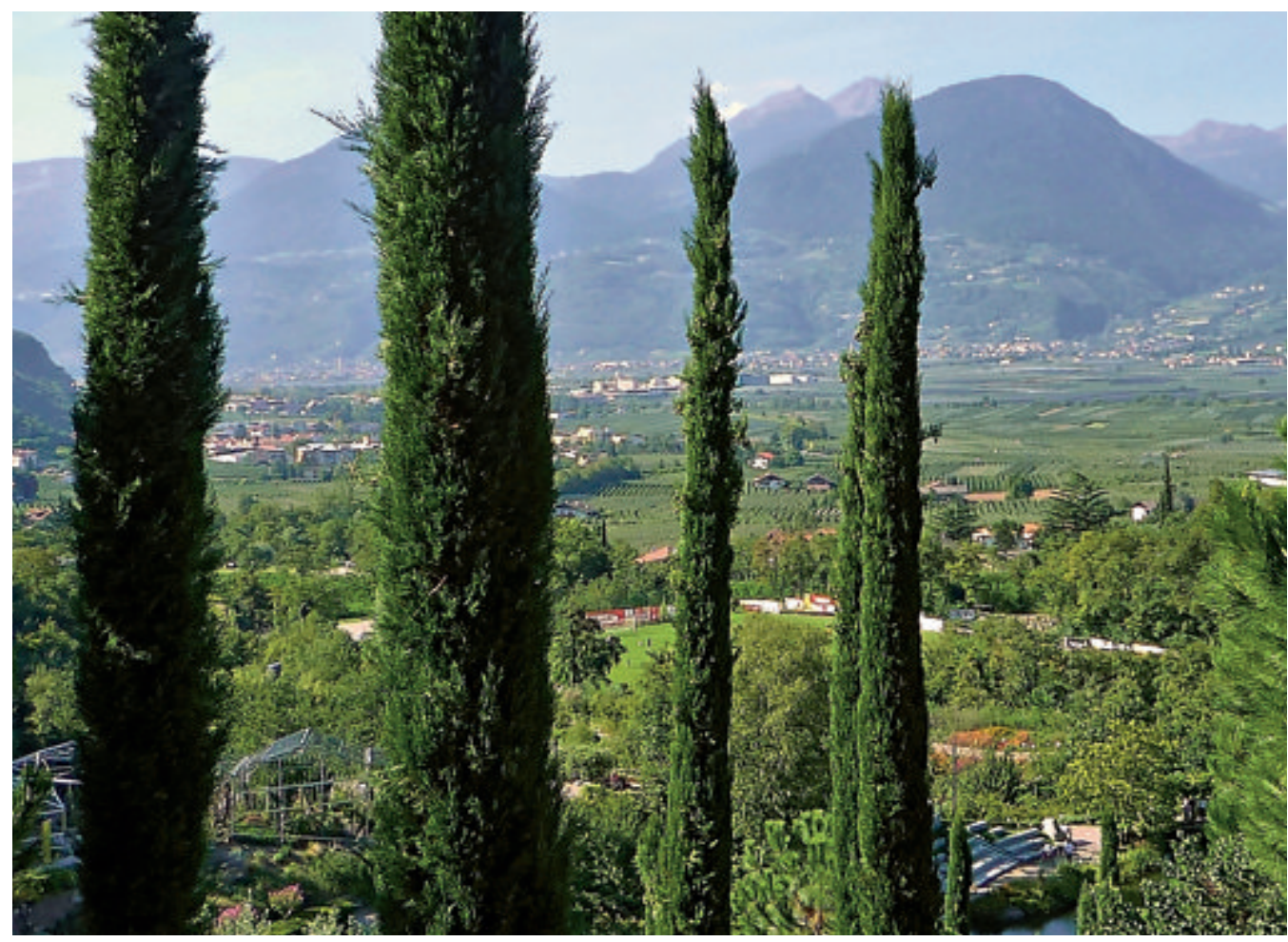

Abb. 1: Blick über die Gärten von Schloss Trauttmansdorff. 
dort - ließ es sich träumen. In der ScrovegniKapelle wurden unvorstellbare Götter-Fresken aus dem 14. Jh. bestaunt. Die Euganeischen Hügel begleiteten unsere Fahrt zur Villa Barbarigo.

Vicenza, Tiepolo-Fresken, das Teatro Olimpico und die Stuck-Altstadt ließen uns ergriffen schauen und die vielfältigen Eindrücke aufnehmen. Aus jeder Ecke grüßten Bauten des großen Palladio. Passend zu unserem Aufenthaltsort war es sommerlich heiß.

Während der kurzweiligen Fahrt auf dem Brentakanal ging es an beschaulicher Landschaft vorbei, in der die Zypressen sich stolz zum blauen Himmel reckten. Ein angenehmer Fahrtwind milderte die Hitze und unsere Reisegruppe genoss die Fürsorge der aufmerksamen Schiffsmannschaft. Das köstliche Fischmenü mundete. Zwischendurch besichtigten wir die von PaLlaDIO gestaltete Villa Foscari, die mit wundervollen Fresken in teils prächtigen, aber auch blassen Farben ausgestattet ist. Zusätzlich gab es die Gelegenheit, die Villa Widmann sowie das Lustschloss und den Park der Villa Pisani zu sehen.

Venedig lässt sich schlecht beschreiben. Die Stadt mit den vielen Kanälen konnte jeder für sich erleben. Zum Bild Venedigs gehören auch der Trubel auf San Marco und dem Canale Grande sowie die Stille in den Gassen und kleine Bars, in denen man einen Espresso genießen kann.

Schnell war eine mit einem intensiven Programm gefüllte Woche vorüber. Zu Hause mussten sich erst einmal die vielen Eindrücke von Sehenswürdigkeiten, Erlebnissen und schönen Begegnungen setzen. Es war eine rundum gelungene Woche.

Auch in Zukunft wird die Gesellschaft der Freunde des Palmengartens interessante Reisen und Tagesausflüge anbieten.

Abb. 2: Die Gruppe lauscht aufmerksam den Erläuterungen zur Basilika des Heiligen ANTONIUS in Padua.

Abb. 3: Drehbrücke am Brentakanal.
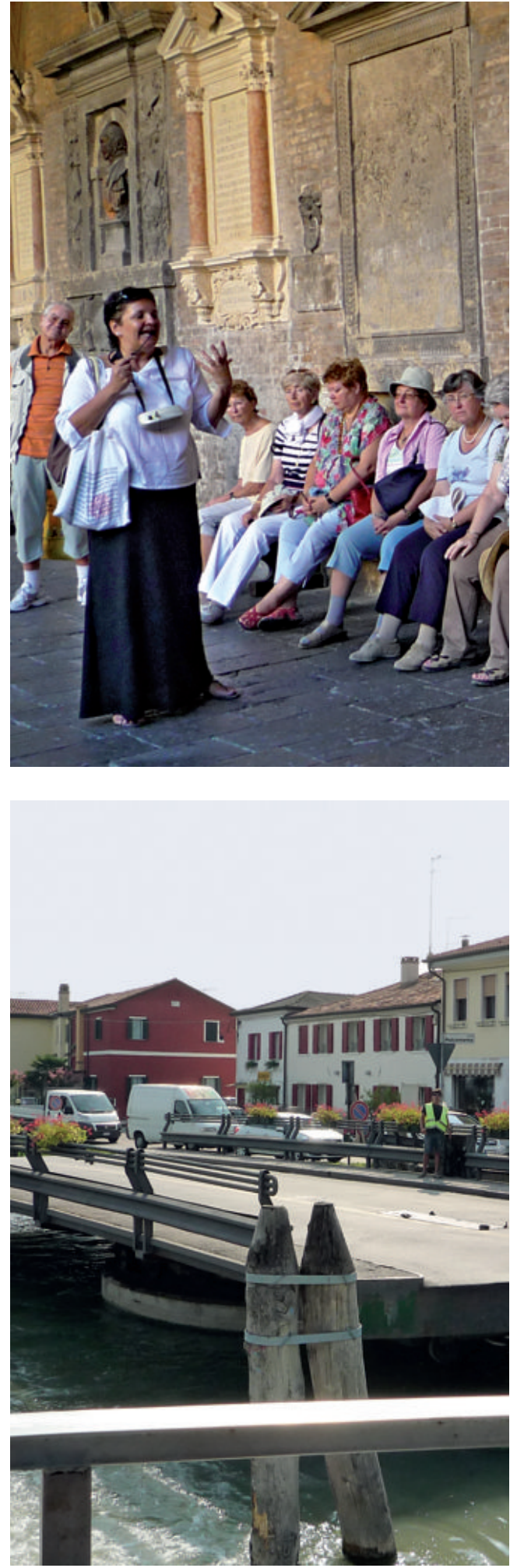